\title{
Parasitism by Syngamus trachea in Blue-and-Yellow Macaw (Ara ararauna)
}

\author{
Jean Henrique Nunes de Paula', Juliana Macedo Magnino Silva², Liria Queiroz Luz Hirano³, \\ Isabela Vieira Carneiro ${ }^{4}$, Nathana Beatriz Martinss ${ }^{4}$ \& Rafael Rocha de Souza ${ }^{4}$
}

\begin{abstract}
Background: Ara ararauna is widely distributed in South America and frequently affected by anthropogenic activities and environmental pressures such as illegal bird trafficking, and habitat loss. Also some endoparasites can threaten their health, and cause their death, or prevent the reintroduction of the animal to its natural environment. The objective of the present work was to report the occurrence of parasitism by Syngamus trachea in an Ara ararauna.

Case: An adult, 900-gram female Ara ararauna from a project for the rehabilitation of the Brazilian fauna was kept in a collective nursery together with 12 specimens of the same species. Their diet was composed of typical fruits of the region, which were offered twice a day, and water ad libitum. The macaws had no previous history of anthelmintic treatment. The specimen evaluated presented progressive weight loss, constant sneezing, and reduced appetite for seven days. During physical examination the animal presented apathy, lethargy, spiked feathers, body condition score of $1 / 4$, frequent sneezing, and inspiratory dyspnea. After this examination, the bird died, and the necropsy was performed. The postmortem findings were pale periocular, oral, and cloacal mucosae, cachexia, and presence of parasites of round shape, reddish color, with length of approximately $0.5 \mathrm{~cm}$, in the proximal portion of the trachea. Another parasite with the same characteristics, but smaller in size, showing Y shape was found in the body. The trachea also showed colorless mucus and petechial hemorrhages in the proximal and middle portions of the mucosa. These parasites were subjected to morphological analysis in the Laboratory of Microscopy of the University Center of Triângulo and were identified as Syngamus trachea.

Discussion: The diagnosis was based on morphological analysis of the parasite. This parasite can be transmitted through infected worms, which are paratenic hosts of $S$. trachea. Chickens may also be parasitized by S. trachea; consequently, they may have contributed to the dispersion of eggs of $S$. trachea in the environment, since they had free access to the entire rural property. There is a positive correlation between parasitism by $S$. trachea and body condition loss in other bird species that may be connected to the lowering of its feed conversion and food consumption. The mechanical irritation caused by parasites in the tracheal lumen was probably the cause of the clinical manifestations involving the respiratory tract, which were characterized by dyspnea and sneezing. Moreover, petechial hemorrhages, increased mucus production within the trachea, and paleness of the visible mucosa are alterations probably caused by traumatic action and the hematophagous habit of the nematode in the trachea of the bird. Climatic and soil conditions can favor the maintenance of $S$. trachea eggs and larvae and the permanence of the verminosis in the environment. Therefore, a strict sanitary control of the animals in conservation projects is necessary, with a routine of coproparasitological examinations. Although the actual epidemiological status of endoparasites in free-living Ara ararauna is unknown, deworming protocols for birds intended for release in natural environments are different from those used in specimens under observation. Birds that will return to free life receive antiparasites only in cases of clinical symptomatology associated with positive tests of verminoses to maintain the natural resistance of the birds to the parasites found in their natural environment. The results of this report, showing the occurrence of infection of Ara ararauna by Syngamus trachea denotes the importance of periodic coproparasitological exams.
\end{abstract}

Keywords: endoparasite, Psittaciformes, syngamosis, gapeworm. 


\section{INTRODUCTION}

Blue-and-yellow macaw (Ara ararauna Linnaeus, 1758) is a macaw parrot species of the Psittacidae family that is widely distributed in South America and part of Central America [24]. It has a short, ventrally arched upper beak, with broad base, and a special joint between the rhinotheca and the maxillary bone, which enables the bird to perform complex movements [10].

Parasitic infections are the major diseases affecting wild animals in captivity. Morbidity and mortality are dependent on the parasite species, parasitic load, nutritional status, immunocompetence, and physiological conditions of the host [2,9].

Syngamus trachea is a nematode whose transmission occurs directly by ingestion of the larva by the bird, which is its definitive host, and indirectly - more commonly - by ingestion of paratenic hosts such as worms, snails, and insects. Insects infected with eggs of $S$. trachea are ingested by the bird and its bloodstream carries them to the lungs and trachea, where they develop and reproduce. This parasite is hematophagous; thus, it causes mechanical damage, anemia, inflammation, and increased mucus production, generating clinical manifestations involving the respiratory tract [4].

Syngamosis has been reported in Galliformes $[7,8,12]$ and raptors, however, the description of parasitosis in Psittacidae species is not found. Thus, the objective of this work was to report an occurrence of Syngamus trachea in Ara ararauna.

\section{CASE}

An adult, 900-gram female Ara ararauna (blue-and-yellow macaw) from a project for the rehabilitation of the Brazilian fauna was examined at a farm in the municipality of Araguari MG, Brazil. The farm contained chickens that circulated freely in the property during daytime, even in the areas near the Ara ararauna nursery. No endoparasite control was performed on domestic animals.

This animal was kept in a collective nursery together with 12 specimens of the same species identified by washers and microchips. The enclosure had length of $9 \mathrm{~m}$, width of $5 \mathrm{~m}$, and height of $3 \mathrm{~m}$, metallic screen, and wood structure, and contained perches of varied size and thickness, feeder and drinker on the ground and suspended, native vegetation, and artifacts for environmental enrichment. Their diet was composed of typical fruits of the region, which were offered twice a day, and water ad libitum.
According to the animal's handler, the Ara ararauna specimen presented progressive weight loss, constant sneezing, weakness, difficulty to perch, remaining most of the time on the nursery floor, and reduced appetite for at least seven days. During physical examination, the animal presented apathy, lethargy, spiked feathers, body condition score of 1/4 (IBAMA, 1994), frequent sneezing, and inspiratory dyspnea. Excreta were collected for coproparasitological examination and the animal support treatment was started. The blue-and-yellow macaw died at the same day, and necropsy was performed.

The postmortem findings were pale periocular, oral, and cloacal mucosae, cachexia, and presence of parasites of round shape, reddish color, with length of approximately $0.5 \mathrm{~cm}$, in the proximal portion of the trachea.

Another parasite with the same characteristics, but smaller in size, showing Y shape was found in the body. It was later identified as Syngamus trachea through morphological analysis carried out in the laboratory of microscopy of the University Center of the Triangle, in the city of Uberlândia MG. The trachea also showed colorless mucus and petechial hemorrhages in the proximal and middle portions of the mucosa.

After the postmortem diagnosis of the bird, two macaws of the same nursery showed similar clinical signs. Therefore, fenbendazole $\left(25 \mathrm{mg} \mathrm{kg}^{-1}\right)$ and ivermectin $\left(0.2 \mathrm{mg} \mathrm{kg}^{-1}\right)$, were administered orally to the beak of each animal after physical restraint using a dip net and leather gloves. Fenbendazole was administered in two doses, with a ten-day interval, and ivermectin was administered in two doses with a 14-day interval. Coproparasitological exams were performed with no detection of the parasite.

\section{DISCUSSION}

This case study reports the occurrence of Syngamus trachea in Ara ararauna, and is the first report of this parasitosis in birds of the Psittaciformes order.

The diagnosis of the disease and identification of the parasite species was confirmed through morphological analysis. Morphological analysis was also used for identification of Syngamidae species in the trachea of Passeriformes in Central Europe [13], denoting that the morphological evaluation is effective to identify these parasites.

Videoendoscopy is the technique used for the diagnosis of syngamosis in humans [18]. However, no description of this method for the diagnosis of $S$. tra- 


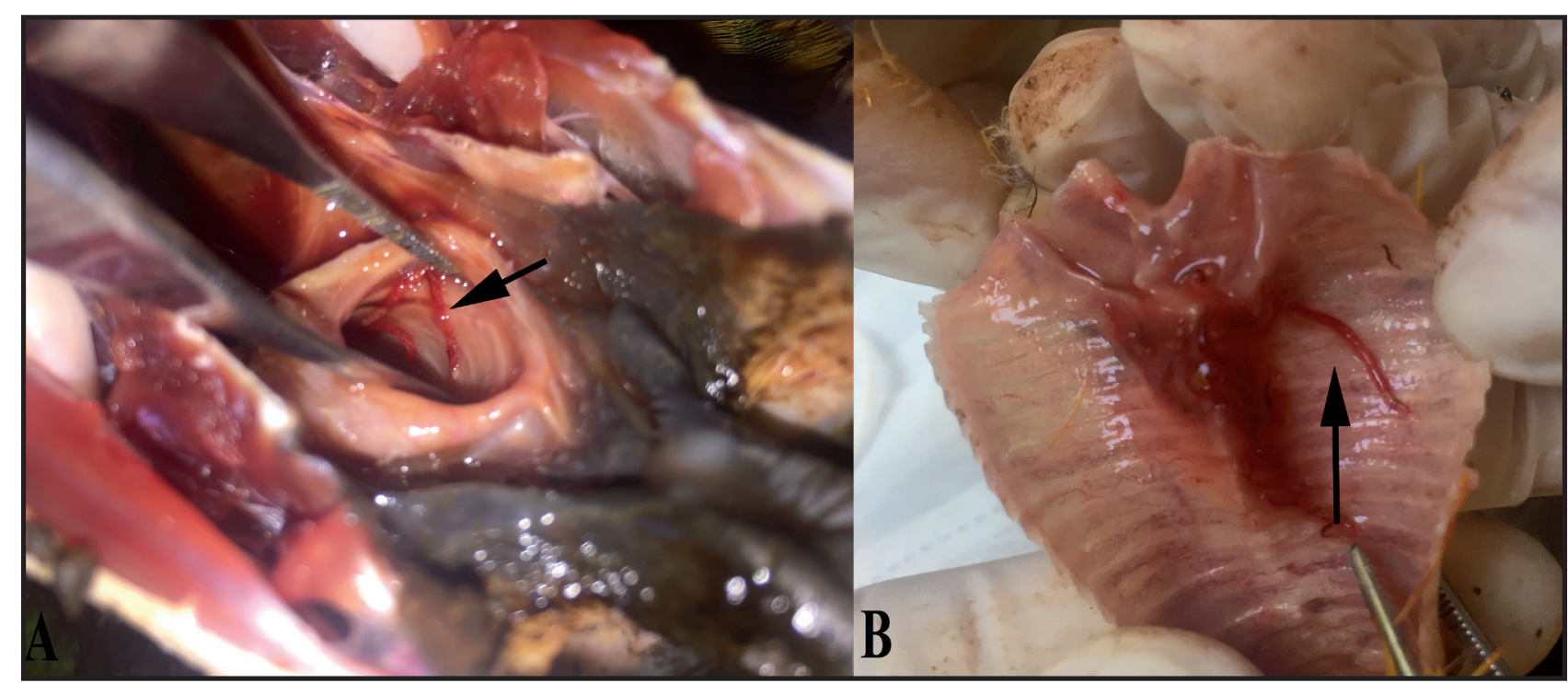

Figure 1. A- Syngamus trachea seen in the rima glottidis of the Ara ararauna. B- Internal view of the trachea of the Ara ararauna, with presence of Syngamus trachea.

chea in birds is found, probably due to its particularities and the reduced size of their tracheal lumen. Thus, the diagnosis is usually made by physical examination of the trachea of these animals, using a light source, and by coproparasitological examination [14].

The transmission of this parasite can occur through infected worms, which are paratenic hosts of the syngamosis [3]. Moreover, chickens may also be parasitized by Syngamidae species [15,19], consequently, they may have contributed to the dispersion of eggs of $S$. trachea in the environment, since they had free access to the entire rural property.

The reduction in body condition score found in the A. ararauna, was also found in a Phasianus colchicus, with positive correlation between parasitism by $S$. trachea and body condition loss [8]. Thus, the body condition loss found in the blue-and-yellow macaw may be connected to the lowering of its feed conversion and food consumption.

Body condition loss may negatively affect the animal reproduction [22] and, combined with the loss of the natural habitat of these birds [5], confirms the need for preservation programs of the Brazilian avifauna.

Regarding the postmortem findings, the mechanical irritation caused by parasites in the tracheal lumen was probably the cause of clinical manifestations involving the respiratory tract [12] of the animal, which were characterized by dyspnea and sneezing. Petechial hemorrhages, increased mucus production within the trachea, and paleness of the visible mucosa are alterations probably caused by traumatic action and the hematophagous habit of the nematode in the bird's trachea [17,22].
Two macaw birds that were in the same enclosure presented clinical manifestation of dyspnea, sneezing, and progressive weight loss. Thus, after the diagnosis of syngamosis in the specimen examined, a prophylactic treatment was performed using anthelmintic medicines based on ivermectin and fenbendazole. Ivermectin controls parasites through mechanisms of inhibition of neuronal activity; fenbendazole (benzimidazole group) molecules bind to tubulin molecules in the parasite, which is a structural protein responsible for the maintenance of cellular homeostasis [1]. The efficacy of these compounds against $S$. trachea and tolerability in birds were described in Phasianus colchicus, and Pavo cristatus, showing high safety $[11,25]$.

Climatic and soil conditions can favor the maintenance of S. trachea eggs and larvae and the permanence of the verminosis in the environment [7]. This indicates the need of sanitary measures consistent with each breeding and management system for the maintenance of the health and well-being of captive birds. A large part of the substrate in the enclosure was composed of earth, making the chemical control of the environment difficult. Therefore, environmental disinfection practices such as sanitary periods between animal lots, and the use of lime and flamethrower is important.

A strict sanitary control of animals in conservation projects is necessary since high animal density and poor sanitary measures contribute significantly to increasing mortality rate [7]. In this context, routine coproparasitological exams assists in the maintenance of the birds' health [22]; these exams show endoparasitoses present in the site, facilitating the preparation of treatment protocols [16]. 
Although the actual epidemiological status of endoparasites in free-living Ara ararauna is unknown [20], deworming protocols for birds intended for release in natural environments are different from those used in specimens under observation. Birds that will return to free life receive antiparasites only in cases of clinical symptomatology associated with positive tests of verminoses to maintain the natural resistance of the birds to the parasites found in their natural environment [21].

In this context, maintaining the animal's satisfactory immune response is essential during rehabilitation. This can be achieved with adequate management, balanced nutrition, and environmental well-being, through environmental enrichment, which result in a better immune response to diseases and correction of acquired behavioral deviations $[1,6,16]$.

This report highlighted the occurrence of infection of Ara ararauna by Syngamus trachea, and the use of fenbendazole and ivermectin in the control and treatment of endoparasitoses.

\section{MANUFACTURERS}

${ }^{1}$ Vetnil. Louveira, SP, Brazil.

${ }^{2}$ Boehringer Ingelheim do Brasil Química e Farmacêutica Ltda. São Paulo, SP, Brazil.

Declaration of interest. The authors report no conflicts of interest. The authors alone are responsible for the content and writing of this paper.

\section{REFERENCES}

1 Almeida M.A.O. \& Ayres M.C.C. 2006. Considerações gerais sobre os anti-helmínticos. In: Spinosa H.S. (Ed). Farmacologia Aplicada à Medicina Veterinária. 4.ed. Rio de Janeiro: Guanabara Koogan, pp.437-461.

2 Catão-Dias J.L. 2003. Doenças e seus impactos sobre a biodiversidade. Ciência e Cultura. 55(3): 32-34.

3 Clapham P.A. 1934. Experimental studies on the transmission of gapeworm (Syngamus trachea) by earthworms. In: Proceedings of the Royal Society of London. Series B. The Royal Society, pp.18-29.

4 Fernando M.A \& Barta J.R. 2008. Tracheal Worms. In: Atkinson C.T., Thomas N.J. \& Hunter D.B. (Eds). Parasitic Diseases of Wild Birds. Oxford: Willey-Blackwell, pp.343-354.

5 Gallardo A.L.C.F., da Silva J.C., Gaudereto G.L. \& Sozinho D.W.F. 2017. A avaliação de impactos cumulativos no planejamento ambiental de hidrelétricas na bacia do rio Teles Pires (região amazônica). Desenvolvimento e Meio Ambiente. 43: 22-47.

6 Garcia L.C.F. \& Bernal F.E.M. 2015. Enriquecimento ambiental e bem-estar de animais de zoológicos. Ciência Animal. 25(1): 46-52.

7 Gethings O.J., Sage R.B. \& Leather S.R. 2015. Spatio-temporal factors influencing the occurrence of Syngamus trachea within release pens in the South West of England. Veterinary Parasitology. 207(2): 64-71.

8 Gethings O.J., Sage R.B., Morgan E.R. \& Leather S.R. 2016. Body condition is negatively associated with infection with Syngamus trachea in the ring-necked pheasant (Phasianus colchicus). Veterinary Parasitology. 228: 1-5.

9 Godoy S.N. \& Cubas Z.S. 2011. Doenças virais e parasitárias em Psittaciformes: uma revisão. Clínica Veterinária. 90(1): 32-44.

10 Grespan A. \& Raso T.A. 2014. Psittaciformes (Araras, Papagaios, Periquitos, Calopsitas e Cacatuas). In: Cubas Z.S., Silva J.C.R. \& Catão Dias J.L. (Eds). Tratado de animais selvagens - Medicina veterinária. São Paulo: Roca Ltda, pp. 614-656.

11 Griffith R., Yaeger M., Hostetter S., Tell L.A., Wetzlich S., Vickroy T., Lillie B., Macfarlane W., Laudenslager T., Whitley E., Dzikamunhenga R. \& Larson W. 2014. Safety of Fenbendazole in Chenese Ring-Necked Pheasants (Phasianus colchicus). Bio One. 58(1): 8-15.

12 Holand H., Jensen H., Tufto J., Soliman M., Saether B.E. \& Ringsby T.H. 2014. Lower survival probability of house sparrows severely infected by the gapeworm parasite. Journal of Avian Biology. 45: 365-373.

13 Kanarek G., Zalesny G., Sitko J. \& Rzad I. 2016. Taxonomic status of Syngamus nematodes parasitizing passeriform hosts from central Europe: morphological, morphometric and molecular identification. Parasitology international. 65(6): 447-454.

14 Llic T., Becskei Z., Gajic B., Ozvegy J., Stepanovic P., Nevadovic K. \& Dimitrijevic S. 2018. Prevalence of endoparasitc infections of birds in zoo gardens in Serbia. Acta Parasitologica. 63(1): 134-146. 
15 Marietto-Gonçalves G.A., De Lima E.T. \& Andreatti Filho R. 2007. Doenças respiratórias aviárias atendidas no laboratório de ornitopatologia da FMVZ- UNESP/Botucatu - SP, Brasil durante os anos de 2005 a 2006. Acta Scientiae Veterinariae. 35(2): 219-225.

16 Melo C.M.F., Oliveira J.B., Feitosa T.F., Vilela V.L.R., Athayde A.C.R., Dantas A.F.M., Wagner P.G.C. \& Febronio A.B. 2013. Parasites os psittaciformes and accipitriformes in Paraíba state, northeastern Brazil. Revista Brasileira de Parasitologia. 22(2): 314-317.

17 Narayanan P.M., Karynakaran G., Ravindran R., Gopalan A.K.K., Clandrasekhar L., Sukumaran S.I. \& Kalarikkal D.C. 2013. Occurrence of fatal syngamosis in emu birds of Kerala. Journal of Parasitic Diseases. 38(2): 241-243.

18 Pulcherio J.O., Silva, E.O.M., Rezende D.P., Barbeira P.B.B., Machado R.S. \& Oliveira A.B. 2013. Human Syngamosis as an Uncommon Cause of Chronic Cough. International Archives of Otorhinolaryngology. $17(4): 413-414$.

19 Quadros R.M., Wiggers S.B., Paes M.P.V. \& Marques S.M.T. 2015. Prevalência de endo e ectoparasitos de galinhas caipiras em pequenas propriedades da região serrana de Santa Catarina. PubVet. 9(1): 1-5.

20 Saindenberg A.B., Gilardi J.D., Munn C.A. \& Knobl T. 2015. Evaluation of fecal gram stains and prevalence of endoparasites in free-living macaws. Atlas de Saúde Ambiental. 3(3): 3-11.

21 Santos P.M.S., Silva S.G.N., Fonseca C.F. \& Oliveira J.B. 2015. Parasitos de aves e mamíferos silvestres em cativeiro no estado de Pernambuco. Pesquisa Veterinária Brasileira. 35(9): 788-794.

22 Shutler D., Alisauskas R.T. \& McLaughlin J.D. 2012. Associations between body composition and helminths of lesser snow geese during winter and spring migration. International Journal for Parasitology. 42: 755-760.

23 Stenkat J., Krautwald-Junghanns M.E. \& Schmidt V. 2013. Causes of morbidity and mortality in free-living birds in an urban environmnt in Germany. EcoHealth. 10(4): 352-356.

24 The IUCN Red List of Threatened Species. 2017. Disponível em: <http://dx.doi.org/10.2305/IUCN.UK.2016-3. RLTS.T22685539A93078598.en>. [Accessed online in November 2017].

25 Umar S., Abbas S., Khan M.I., Nisa Q., Younus M., Agil K., Qayyum R., Yagoob M., Ali A., Yaseen M.A. \& Shah M.A. 2018. Safety of fenbendazole in common peafowl (Pavo cristatus). Pakistan Journal of Pharmaceutical Sciences. 31(1): 159-167. 